\title{
CURRENT PRACTICES AND FUTURE TRENDS IN FOREST INSECT CONTROL ${ }^{1}$

\author{
BY R. E. BALCH ${ }^{2}$
}

The inclusion of this subject in the program implies a close relation between silviculture and protection from insects. It is a welcome association of ideas that deserves more general recognition. In many respects progress in insect control is dependent on progress in silvicultural management. There was a time when the connection between the forest entomologist and the practicing forester was very vague. The entomologist was expected to study his insects and discover ways and means of preventing them from damaging trees while the forester proceeded with his job of cutting them. The trend away from this isolationist attitude has been notable in recent years and I would like to associate with it the name of F. C. Craighead, a United States forester who specialized in entomology and did much to bring the thinking of entomologists and foresters closer together.

Craighead also worked in Canada. His associations with J. M. Swaine and J. J. de Gryse have been followed by increasing collaboration between the forest entomologists of both countries that has led to numerous co-operative undertakings. Joint meetings have become an annual affair both in the East and the West.

\section{RESEARCH}

Before introducing the subject of current and future practices I would like to say something about trends in research. The control of forest insects is not a simple problem. It is concerned with a large number of species, each with its peculiar habits and its particular place in the ecology of the forest. It is not just a matter of finding something to "kill the bug" before it kills the trees. Like public health, its ultimate objective must be not only to control outbreaks but to prevent them, and whether we aim to control ${ }^{3}$ or to prevent them, we must understand their nature. Before undertaking to control an outbreak, it is well to be able to foresee its probable natural course and the probable long-term results of any measures applied. In other words, we should know the ecology and dynamics of the insect populations concerned: what determines their rise and fall, and what natural control factors are capable of preventing them reaching the level that causes economic damage. We cannot afford to plan our protection on a basis of either panic or complacency or of pure guesswork. Judgment will always be involved but the object of research must be to reduce guesswork to a minimum.

The epidemiology of any one species presents a complex problem. Its study involves the measurement of populations at a number of places over a number of years if we are to go beyond guesswork. This is time-consuming work

1 Presented at the joint annual meeting of the Canadian Institute of Forestry and the Society of American Foresters held in Montreal, Quebec, in November, 1952.

Contribution No. 73, Division of Forest Biology, Science Service, Canada Department of Agriculture.

2 Dominion Entomology Lab., Fredericton, New Brunswick. Immediate past president of the C.I.F.

3 The term "control" is used here of any measures designed to limit insect activity whether they seek to influence the length of intensity of an outbreak or whether they only serve to they seek to infuence the length of intensity of an outbreak or whether they only serve to
protect specific areas from serious damage while the main outbreak runs its natural course. 
and presents difficult problems in sampling, but it is fundamental to any sure advance in our ability to predict the occurrence and course of outbreaks. It is also fundamental to the wise choice of control measures and the reliable interpretation of their results.

This emphasis on quantitative studies of insect population in the forest is one of the trends in current research and must provide the background for much of the future research in other fields of forest entomology. An example is the study of spruce budworm populations by R. F. Morris as part of the Green River Project. The specific purpose is to determine how they are influenced by different stand types that result from management, or lack of management. It is an attempt to test and refine definitions of susceptibility or vulnerability by the most exact methods available for the study of population trends under endemic as well as epidemic conditions.

Another trend in research that should be mentioned is in the field of biological control. Hitherto this has been concerned with parasites and predators and this work is being continued. A more recent development is the study and use of insect diseases. Their possibilities have been neglected in the past, partly because they were considered to belong to a sort of no man's land between entomology and pathology-a state of mind now happily corrected. It was given an impetus by the discovery of a virus attacking the European spruce sawfly that proved of major importance in bringing to an end the serious outbreak of this insect in the 1930's. Study led to methods of propagating the virus and liberating it in areas where it was absent. Work in this field has been facilitated by the construction of a laboratory for the purpose at Sault Ste. Marie, Ontario. During the past three years another virus has been found and is being put to use against another introduced insect, the European pine sawfly. F. T. Bird has shown that it can be propagated economically and applied at high dilutions with striking control effects in plantations. The method was further developed this year by distributing the virus from an aeroplane. It is expected that next year the Ontario Department of Lands \& Forests, together with land-owners, will employ the disease in control measures by aerial spraying. Tests of the virus are also being made in the United States.

It seems probable that other viruses of value will be found and aerial spraying of the future may not be confined to chemicals. The discovery of new methods of this kind should not, however, lead to the assumption that they can be widely used. Viruses, for instance, are highly specific and we will be dependent on those that exist in nature-at least until much more is known about them. Relatively few may be found that are sufficiently virulent or can be successfully manipulated, but the field is a promising one and continued intensive research is warranted.

One other important development is the intensification of research on aerial spraying of forests with DDT. United States entomologists took the lead in this after the war and made considerable advances in the techniques of application. Improvements in these techniques will undoubtedly be made but the stage has been reached where large-scale operations are being undertaken. The potentialities of the method can only be finally determined in this 
way. The paramount research problem now is to discover the long-term effects on insect populations and on the natural control complex-another of those difficult problems in quantitative population study.

Finally, I may mention the development of forest insect surveys, which form a basis for research as well as control. They are now organized in both the United States and Canada. In Canada, a continuous annual survey is undertaken by the Division of Forest Biology in co-operation with the provincial services and the industry. It is providing for the first time a full record of the development and extent of outbreaks that will be invaluable in studies of epidemiology. One important purpose is the detection of outbreaks in early stages so that warning may be obtained of the need for adjustments of working plans or the use of control measures. It is a means of detecting the occurrence and spread of introduced species and determining the need for work on biological control. At the same time data are being accumulated on the biology of destructive and beneficial species, their habits and potentialities. The field work is done by trained forest insect rangers who co-operate with provincial rangers and company staff. The trend is toward more quantitative methods and more exhaustive analysis of the data to determine relationships between the various species, their natural enemies and their hosts, and between outbreaks and climatic and stand factors.

\section{Current Practices and Trends}

To pass on to a discussion of current practices in forest insect control presents a difficulty of definition. If "practices" mean customary usages, it is doubtful if we have many, except for such cases as the methods of handling logs to avoid borer attack. Spraying and other methods used against the gipsy moth and many shade tree pests may have become sufficiently habitual to be called practices, but will not be considered here. Most of the serious attempts at control have been adaptations to fit the biological and economic circumstances of particular outbreaks. To a large extent they have been trials that have led to improvements in technique, or to abandonment of the method, according to their success or failure. The methods have been too varied, or too limited in application, to be called "practices". It will probably be best to classify them as direct or indirect, and consider the relative merits of these two types of control by taking a few examples.

The indirect methods include all biological or silvicultural means for improving natural control or the resistance of the forest.

\section{Biological Control}

In biological control the policy in Canada is to carry on a continuous program of study of the parasites, predators and diseases of our major pests and to introduce from abroad those that seem likely to be a valuable addition to the complex of natural control. This work is directed chiefly at pests that were accidentally brought to this country from Europe before the days of plant quarantine, but parasites from other parts of our own continent are also being tried. A considerable number of parasites and predators have been successfully established and are contributing to the control of such insects as the European spruce sawfly, the larch sawfly, the satin moth, and the balsam 
woolly aphid. The use of diseases is in its infancy but as already mentioned two viruses have been employed to good effect. The European spruce sawfly is an example of a serious pest that was unattacked by parasites or disease and is now under satisfactory control by the combined effects of a virus and several species of introduced parasites. Present work is concerned with the balsam woolly aphid, the spruce budworm, and a recently discovered introduction, the European winter moth.

\section{Silvicultural Control.}

An example of silvicultural control is the selective cutting of high risk trees in the Western States to reduce attack by the western pine beetle. The use of silvicultural methods to reduce insect damage cannot be called a "current practice" in Canada. Obviously it cannot precede the practice of silviculture. The principles of creating more resistant stands have been outlined for a number of species. In general, they involve control of stand composition, rotation age, and maintenance of vigour of growth and they do not conflict with normal good silvicultural practice. They are being given some consideration in the formulation of management plants and cutting regulations, but the value of good silviculture and the importance of developing silvicultural practices favourable to the prevention of insect damage are not yet generally recognized. This is due in part to reluctance to adopt cutting practices that appear to conflict with the immediate economic objectives of management, especially if the protective value is dependent on their application to large areas of varied ownership. It is due also, in many cases, to the difficulties of obtaining convincing evidence that silvicultural methods will be effective, at least in the sufficiently near future to interest the present generation of operators. This evidence is being slowly accumulated. It is already sufficient to warrant more general consideration.

The spruce budworm will again serve as an example. Although much remains to be learned about its epidemiology, studies of past outbreaks indicate that, although they are initiated by climatic factors, they have become most severe in areas where the predominant tree is balsam fir and their destructiveness tends to increase with the area and age of the balsam stands. Also, the chance of the survival of the trees increases with their rate of growth. The objectives of management that are indicated if budworm hazard is to be reduced are: (1) a short rotation for balsam fir; (2) an increase in the proportion of spruce or other species; (3) maintenance of vigour of growth; and (4) avoidance of continuous stands of mature or overmature balsam, especially if even-aged.

There may be differences of opinion about the degree of protection that can be obtained by such management. It is difficult to obtain conclusive evidence experimentally but research to date seems to support the conclusion that if these objectives can be attained, the losses from this insect would be greatly reduced and, with the rapidly improving facilities for more intensive management, they would not exceed the capacity for salvage. We expect to add considerably to our knowledge of this subject from studies of the present outbreak.

The question whether such objectives are attainable presents problems in 
both silviculture and management. In areas such as northern New Brunswick and the Gaspé Peninsula, the major disturbances, such as windfall and budworm outbreaks, are followed by stands composed largely of balsam. Present cutting practices produce the same result. Fire is the only exception, and this is far from acceptable as a silvicultural tool in this country. Is it practicable to decrease the percentage of balsam fir? The immediate problem is to cut the mature and overmature balsam, of which there are large areas, rather than the more resistant spruce or the younger stands. The possibility of this is limited by economic and operational considerations, but it is often lost sight of between outbreaks. Also, there are large areas of even-aged second growth balsam that present problems in management if they are not to become the next great budworm hazard. Those that originated from the previous outbreak will mature at the same time in about 20 years. How can they best be managed to maintain vigour of growth and to avoid large continuous mature stands?

These problems are not simple, but I do not think they are insoluble. Our forests are becoming more accessible, the principle of sustained yield is becoming widely accepted, the silvicultural needs of our forest types are becoming better known, and new uses of secondary species are being found. In so far as management takes advantage of these opportunities for improving cutting methods and regulation of cut, there will be an improvement in the general resistance of the forest to insect attack. Good management is an essential basis for insect control. It not only increases resistance but facilitates the use of direct control measures and salvage.

\section{Aerial Spraying}

Direct methods are those that destroy the insect by chemical or physical means. A good example is the control of bark beetle (Dendroctonus spp.) outbreaks in the West by peeling, burning or spraying the infested trees to destroy the brood. When thoroughly carried out, it has been successful with the more aggressive species. With the less aggressive species, such as the western pine beetle and the eastern spruce barkbeetle, its value is dubious and it has been replaced by selective logging of susceptible trees.

At the present time more interest is attached to direct control of defoliators by aerial spraying, which has been used on an increasing scale in recent years. Aerial application of insecticides is not new. It has been used in North America and Europe on a limited scale over the past 30 years. Dusting was undertaken in Canada experimentally as early as 1927 . Until the discovery of DDT, however, it was considered to have very restricted value on this continent. As already mentioned, the high toxicity and residual effect of DDT stimulated further research and this culminated in large aerial spraying operations in the western United States. Many of the operational problems were solved and it was shown that good coverage could be obtained at a reasonable cost per acre. Of particular interest to Canada was the very high degree of success reported against the spruce budworm-an insect that had proved a difficult subject for control by insecticides. Some extensive trials were made by the Ontario Department of Lands \& Forests in 1945 and 1946. Although successful in many respects, they did not provide conclusive evidence regarding the effec- 
tiveness of the method. In 1952, the Canadian International Paper Company, in co-operation with the Provincial Government, sprayed an area of 300 square miles of budworm-infested forest in New Brunswick.

This operation was important for several reasons. It covered the largest single block of forest yet sprayed. It presented problems of topography, climate, and logistics that are typical of much of the budworm-susceptible forest of Eastern Canada, and probably as severe as are likely to be encountered. It showed that these problems can be solved with good organization and attention to detail--as was provided by B. W. Flieger who directed the project. It demonstrated the necessity for a solvent that would keep DDT in solution at low winter temperatures and discovered such a solvent. In short, it provided the necessary evidence that adequate coverage can be obtained to kill the budworm, and it is likely to lead to still bolder attempts to protect the valuable pulpwood forests of the Province from serious damage.

The results were studied with care, and will continue to be studied. The amount of spray deposited was checked throughout the whole area. The insect population was sampled throughout the season at a large number of points in the sprayed area, and in a comparable unsprayed area. The mortality due to spraying ranged from 99 to 100 per cent. As far as killing the budworm was concerned, the project was extraordinarily successful.

The amount of protection given to the forest and the long-term results are less easily estimated. The part of the area sprayed early showed considerable growth of new foliage. The infestation, however, was very heavy and the part sprayed a week or more later, owing to unusually unfavourable weather, had the new foliage destroyed, although feeding on the old foliage was prevented. Extremely heavy moth flights occurred in northern New Brunswick and resulted in considerable reinfestation, although the egg population was decidedly lower on the sprayed than on the unsprayed area. It can only be concluded at the present time that some valuable protection was given to the trees, but the long term effects depend on the future development of the outbreak. The severity of the outbreak and unfavourable weather provided a severe test and the results suggest that spraying is a practicable method of preventing mortality.

There is still much to be learned about the potentialities of spraying, and its proper place in control, but I will suggest one or two generalizations that seem to be warranted by present knowledge. They are not conclusive but should be carefully considered and checked as work progresses, for they have an important bearing on policy in the use of spraying.

1. Aerial forest spraying is a practicable method of limiting attack by defoliators, and also some other insects (such as the white pine weevil in plantations). It should be used when biological and economic considerations warrant it. Values to be protected nust, of course, be carefully calculated with due regard for the probable date of cutting and the silviculitural condition of the stand.

2. In the case of defoliators, such as the spruce budworm, that occur in considerable numbers over large areas, it is not biologically sound 
or practicable to attempt to prevent outbreaks by spraying, or even to control their duration. That is more likely to be achieved by biological or silvicultural methods.

3. In general, spraying against such insects should not be undertaken until the degree of defoliation and the numbers of the next generation of the pest indicate that it is necessary to prevent killing of the trees. The objectives will then be to protect the more vulnerable stands from fatal injury while natural factors terminate the outbreak.

4. When spraying becomes necessary it should aim at wide coverage of the heavily infested area to reduce reinfestation and be applied as early in the season as the habits of the insect permit to give the maximum protection from current defoliation.

Spraying is the only method that will deal with emergencies such as the present widespread outbreaks of the spruce budworm. The initiative of the industry and governments in co-operating to develop its use marks an important trend, and something of a milestone, in forest protection. At the same time it is not so much an alternative to biological or silvicultural methods as an unfortunate necessity in their absence.

\section{CONCLUSIONS}

In bringing to an end these rather cursory remarks about trends in forest insect control I would like to say they do not pretend to cover more than a few aspects of the subject. I will leave it to other speakers to do better justice to work in the United States and Western Canada and to other points of view. The intention has been to suggest discussion with the aid of one or two exaraples of particular interest at the moment in Canada. I might conclude by repeating some points I have tried to make.

1. Forest insect control must be approached from an ecological point of view and based on a knowledge of the ecology of the insect populations concerned and the forest types in which they occur.

2. The ultimate objective is prevention of destructive outbreaks by biological or silvicultural methods of improving natural control and resistance of the forest. This objective, however, will never be completely reached, and direct methods must be employed in those cases where the indirect methods are not possible, or have not yet been put into practice.

3. Aerial spraying with insecticides has been developed to a point where it is a practical method in certain cases. It should be used with discretion, but boldly when necessary for the preservation of a valuable forest. Instead of disturbing the 'balance of nature', it may in such cases serve to correct a lack of balance already present, and prevent the further disturbances that would follow the death of the stand. Its long-term effects, however, need careful study.

4. Direct methods such as spraying should not conflict with biological or silvicultural methods, but should complement them. Good forest management is an essential basis for prevention or control. Progress toward the creation of more resistant forests, however, may need 
to be protected by spraying in order to prevent the complete disruption of management plans. No method is a cure-all. Each pest and each outbreak is a separate problem. The trend should be toward a wider and more effective application of all three methods as our knowledge increases through research and experience. 